\title{
Preventing neglected club feet in Uganda: A challenge to the health workers with limited resources
}

\author{
E.K. Naddumba, MMed (Surgery), (MU), FCS (ECSA), Senior Consultant Orthopaedic Surgeon, Department of \\ Orthopaedics, Mulago Hospital, Kampala, Uganda
}

\section{SUMMARY}

Neglected clubfoot deformity is one of the commonest musculoskeletal disorders in Uganda. It is as a result of failure to provide treatment to the congenital clubfoot deformity during the infancy period due to limited resources. The incidence of clubfoot in Uganda is estimated to be $1 / 1000$,like elsewhere, globally. The population of neglected clubfeet in the country is approximately 10,000. There are 20 orthopaedic surgeons in the country with a population of $\mathbf{2 8}$ million. The treatment in the past has been surgical after failed conservative treatment. With limited resources it is not possible to attend to all clubfeet in the country that would require surgery. The Social economic impact of failure to treat this deformity is great resulting in poverty to the families, and the country. The Uganda Sustainable Clubfoot Project has been established in the country whose Goal is to contribute to elimination of the neglected clubfoot in the country. The methodology is discussed in the presentation with a focus for developing capacity for early detection, treatment using the ponseti method, raising awareness of the health workers and the public, and political support.

\section{INTRODUCTION}

Neglected clubfeet is one of the commonest congenital musculoskeletal disorders in Uganda. It is as a result of failure to provide the correct treatment in the infancy, or first two years of childhood. This is attributed to failure to detect the deformity at birth or early infancy, limited health units countrywide to provide the correct treatment, few orthopaedic surgeons and technicians in the country, scarcity of materials to use during management, and ethno cultural beliefs. The incidence of neglected clubfeet in Uganda is estimated be approximately 10,000 (1). The incidence of congenital clubfoot globally is $1 / 1000$, with a male to female ratio of 2:1 (2-5). Uganda with a population of 28million and birth rate of $3.5 \%$ annually (7), has only 20 practicing Orthopaedic surgeons in the country with the majority practicing in the capital city with a focus to trauma and neglect to the rest of the orthopaedic diseases.

Untreated clubfeet has a high morbidity (7-9) and serious social economic impact to the patient, parents or caretakers, the community, service providers hence contributing to the poverty in the nation. Children with neglected clubfeet live a miserable life. They are forced to walk on the dorsum of these stiff deformed feet, with resultant chronic pain, ulcerations and infection. To avoid this complication, they are forced to put on ugly sandals made from old car tires since they are unable to fit in the regular shoes. They are unable to mix freely with their peers because of despise or stigmatization, and as a result few are able to attend school.

The caretaker's are often the productive mothers in the society, who are forced to neglect their social obligations in the society, and divert their attention to these affected children trying to find a solution to the problem. Treatment of neglected clubfeet is surgery (10). The patient has to undergo several surgical procedures often with unsatisfactory results (10).

The Uganda Sustainable clubfoot Project (USCCP) has therefore been established in the country with a Goal of making available in a sustainable fashion, a universal, effective, efficient, and safe Ponseti treatment method (11) for the congenital clubfoot deformity in Uganda and with a purpose of eliminating the neglected clubfeet as a significant cause of musculoskeletal disability and poverty in Uganda in accordance with the first of the UN's Millennium Development Goals of Eradication of Extreme Poverty and Hunger (12).

\section{MATERIALS AND METHODS}

Following a pilot study by the Uganda Club foot Project (1999 to 2003), through which the Ponseti Method was tested with excellent results, The Uganda Sustainable 
Clubfoot Care Project (USCCP) was established. The USCCP is a partnership between Makerere University Department of orthopaedics, University of British Columbia in Vancouver, Canada, Institute of Public Health of Makerere University, Ministry of Health of Uganda, and Children's orthopaedic Rehabilitation Unit (CORU), Uganda. The stakeholders from these institutions met and after understanding the pathology and workable solution using Levine's principle, reached a consensus within administrative area, secured Funding of CAD\$1.8million from the Canadian International Development Agency (CIDA), identified local champions, and defined the Goal of the project. A public Health approach was recommended to be followed with the following methods in order to solve the problem of neglected clubfoot in Uganda:

1. Build capacity for detection of clubfoot deformity at birth or at the $1^{\text {st }}$ day of infant/neonate immunization:

This involved training of midwives to detect the deformity at birth, sensitization of nurses who immunize the babies in order to detect those babies who are delivered in the homes by Traditional birth attendants, photograph of a child with clubfoot was recommended to be included on the child immunization card as an aid for detection by the nurses, public awareness campaigns for early detection and referral to the established club foot clinics country wide through posters, TV and FM radio stations.

2. Build capacity to treat the deformity:

This involved training of trainers in the Ponseti technique to include orthopaedic surgeons, orthopaedic officers and, orthopaedic technologists conducted at CORU with a purpose of upgrading clubfoot skills at the National, Regional and all District Hospitals in Uganda. Establishment of a chain of clubfoot clinics at the National Referral Hospital, Regional and District Hospitals in the Country.

Ensuring adequate supply chain by Ministry of Health for materials used in the Ponseti Method, which includes plaster of paris, cotton wool, and Steenbeek Foot Abduction Braces (SFAB).

Incidence surveys to determine the magnitude of the problem for planning purposes and budgeting for the resources, and ethno cultural surveys to determine factors responsible for the magnitude of neglected clubfeet in the country were recommended.

3. Capacity to teach:

Upgrading of curricula of medical students at Makerere, Mbarara and Gulu Universities, postgraduate students of orthopaedics and general surgery at Makerere University, paramedical students of orthopaedics and orthopaedic technology at Mulago Paramedical School, and school of nurses and midwives was recommended. This was to include a training module on Ponseti Method. By 2010,80\% schools of higher learning in Uganda mentioned above will have the capacity to detect and treat clubfeet using the Ponseti Method.

\section{The Ponseti method:}

Was recommended because of its long-term $78 \%$ good/excellent outcome at 25 years of follow up. It involves weekly manipulations of the deformity in a staged manner beginning with the midfoot deformity, and finally correction of the hind foot contractures by a simple Tendo Achilles Tenotomy normally after five to six casts, and then foot bracing of the corrected deformity day and night for there months, then at night only for the next four years with the SFAB.

During the casting phase, foot correction is monitored using the Columbian Club Foot Scoring System (13).

\section{RESULTS}

On the $22^{\text {nd }}$ of May 2005 , the USCCP was officially launched in the Country by the Vice President of The Republic of Uganda who directed that the Ministry of Health adapt this cheaper method of treatment of congenital clubfoot in all its hospitals.

Capacity for detection: A total of 296 nurses and midwives at Mulago National Referral Hospital, three Missionary Hospitals in Kampala, and six Regional Hospitals in the country were trained and equipped with the capacity to detect congenital club feet at birth, then refer to the established clubfoot clinics in the country. In addition, educational posters of the Pilot Project were distributed in the hospitals where clubfoot clinics have been established for public sensitization and awareness. 
The inclusion of a picture of clubfoot on the immunization card is yet to be undertaken by Ministry of Health. Public awareness campaigns are also yet to be conducted.

Capacity to treat: A total of 12 clubfoot clinics have been established in the country with the main one at Mulago Hospital, eight at the Regional and the rest at the district hospitals.

They are run by the trained orthopaedic officers and supervised by an orthopaedic coordinator of the project. The regional orthopaedic surgeons at each of these clinics carry out the tenotomies. The capacity of trained staff for these units is shown in Table 1.

Table 1

Trained staff in the Ponseti method in the period 2005-2006

\begin{tabular}{lr}
\hline Orthopaedic Officer students & 100 \\
Nurse/Midwives & 296 \\
Medical students & 49 \\
Orthopaedic Residents & 4 \\
Orthopaedic officers & 43 \\
Physiotherapists & 6 \\
Orthopaedic Technicians & 18 \\
Orthopaedic Surgeons & 6 \\
\hline Total & 522 \\
\hline
\end{tabular}

Material for use at these clinics to include Plaster of Paris is supplied from the National Medical Store on Credit line by Ministry of Health. Ministry of Health contributed Ug Shs 2 million towards production of SFAB, which have also been distributed to these units.

The estimated budget for clubfoot treatment country wide for a year using Ponseti method is approximately Ug Shs 137,600,000/= (Table 2).

Table 2

Estimated budget for materials

\begin{tabular}{lcc}
\hline Materials & $\begin{array}{c}\text { Unit cost per child } \\
\text { (Ug Shs) }\end{array}$ & $\begin{array}{c}\text { Total cost/ } \\
\text { year/1600 children } \\
\text { (Ug Shs) }\end{array}$ \\
\hline POP & $20,000 /=$ & $32,000,000 /=$ \\
SFAB & $11,000 /=$ & $105,600,000 /=$ \\
\hline Total & $31,000 /=$ & $137,600,000 /=$ \\
\hline
\end{tabular}

Surveys and studies: Ethno cultural survey has been conducted and completed. The findings demonstrate the barriers affecting treatment of children in Uganda born with clubfoot, the main being social economic, cultural beliefs and luck of knowledge about the condition and its treatment/treatment centers.

The List of some of these factors is shown in the Table 3.

Table 3

Barriers affecting access to treatment of patients with clubfeet

- Ignorance about aetiology/causative factors

- Lack of awareness for treatment of the condition

- Cultural beliefs about aetiology, and hence treatment seeking behaviour

- Challenges of the process, fear of surgery, cost implications, etc

- Other responsibilities by the mothers or caretakers who have big families

- Poverty

- Challenges of the process to get access to the service providers.

Failure to treat the clubfoot at birth or soon after results in neglected clubfoot as shown in Figure 1.

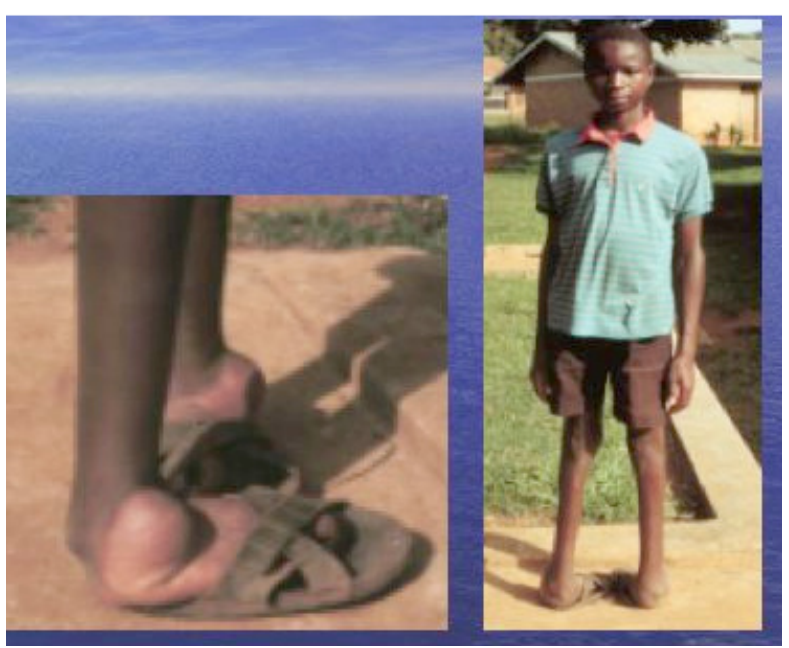

Figure 1: Neglected clubfoot

This patient can only wear modified sandals as protective gear to his deformed feet. 
Incidence survey: This is on going. Data is being collected from eight major hospitals with an intention of examining 100,000 live births. The hospitals include Mulago, Nsambya, Rubaga; Mengo, Mbarara, Mbale and Jinja.The incidence among 4200 babies seen so far is 1.2/1000. (MARIEK), with a male to female ratio of 3:1.

Capacity to teach: The curricula for instititutions of Higher Learning at Makerere Medical School for undergraduates and postgraduate students of orthopaedics and general surgery, paramedical schools for the orthopaedic officers and orthopaedic technology, and for the nurses and midwives, were upgraded to include a module on how to manage clubfoot and the Ponseti method. The training modules for all these cadres have been published in a book by Lynn Staheli (14) to be distributed to all these institutions.

The Ponseti method: This is being practiced countrywide in 12 hospitals. The challenge so far is to make it country wide in a sustainable manner due to limited human resource and capacity for support supervision. Patient attendance is also still low due to luck of public awareness, and social economic factors, especially poverty and distance to travel by the patients to the clinics.

\section{OUTCOME EVALUATION}

Data is being collected in eight major hospitals in Uganda on 1000 babies born with clubfeet, each baby if followed up for a period of 4 years, to determine if the Ponseti Method is effective in Uganda. This includes the CCS during each visit in the casting phase, and also during the bracing phase. It is too early to be analyzed.
Surgery at Mulago on neglected clubfeet and resistant clubfeet has not been practiced during the last two years (Figure 2). Neglected clubfeet are now being operated on at Mengo (CORU), and also in upcountry hospitals by the orthopaedic team during the outreach program.

\section{DISCUSSION}

Neglected clubfoot is a congenital deformity characterized by severe mid foot and hind foot contractures. The fore foot is severely adducted, inverted and in varus position, while the hind foot is in marked equinus, and adducted $(8,9)$.

The pathology is mainly due to the deformed and malaligned head of the Talus which has an abnormal head/shaft angle of less than $45^{\circ}$, resulting in dislocation of the talo navicular joint, and malaligment of the talocalcaneal and calcaneal cuboid articulations. The soft tissue structures (tendons and ligament) at the posterior and medial aspect are contracted. As a result, the child tends to walk on the dorsal lateral surface of the foot resulting in painful callosities and ulcerations.

The deformity if picked at birth or early infancy has good prognosis when offered the conservative management of serial manipulations, and casting, followed by prolonged bracing to avoid recurrence $(8,9)$. The conservative management is successful up the age of two years. Beyond this age, the contractures get stiffer and the foot skeletal structures get more deformed hence a need for limited or several surgical procedures to correct the deformity.

The surgical procedures include posteromedial release and posterior capsulotomy. After the age of four years, one may consider some bony procedures
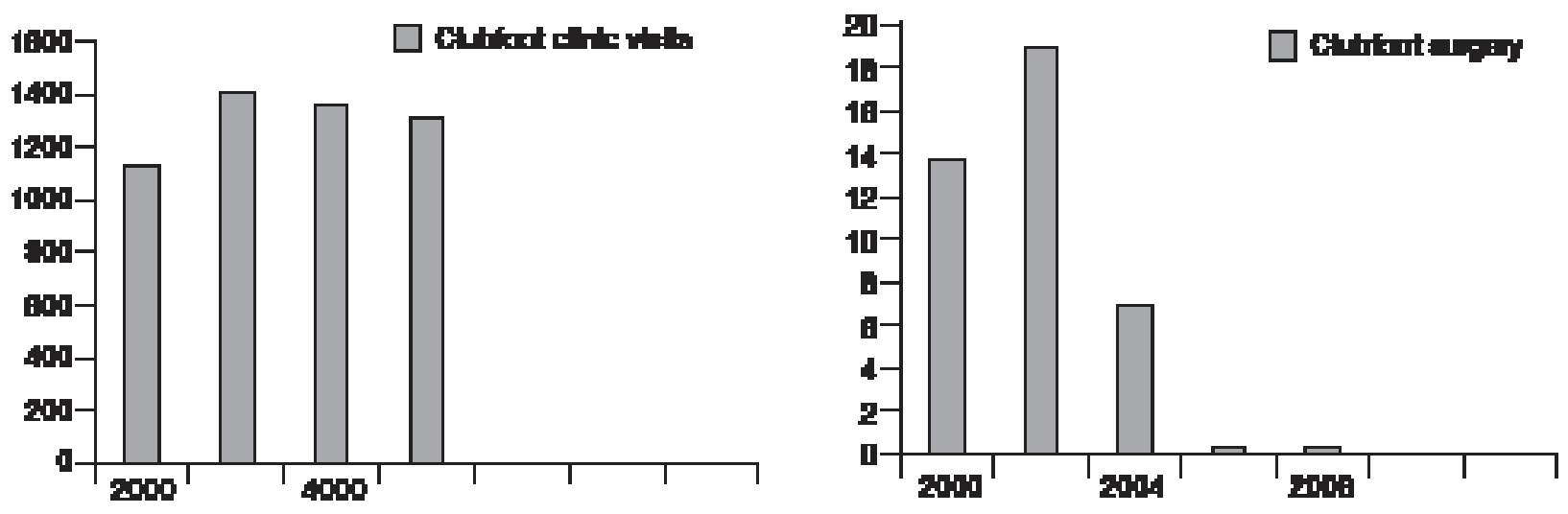

Figure 2: Clubfoot clinic attendance and surgical operations between the year 2000 and 2006 at Mulago in Uganda 
like postero lateral wedge osteotomy of the calcaneum (Dewers), or dorsal wedge osteotomy of the talus.

In older children above the age of 12 years, triple arthrodesis is recommended.

These bony procedures often result in a near to normal foot correction, but with poor results due to foot stiffness and chronic pain.

The Ponseti method being practiced has been proved to have $78 \%$ good to excellent results after 25 years follow up hence recommended in this project (9,14-18).

Other non-operative methods include the Kites method (10), which was being practiced in Uganda for decades before Ponseti.

The explanation for the high prevalence of neglected clubfoot in Uganda is mainly due to social economic factors as demonstrated through the ethno cultural studies. Lack of infrastructre, few orthopaedic surgeons in the country could also be a contributing factor.

Inadequate supply chain for Plaster of Paris, cotton wool and braces are also factors to consider.

The treatment method of Kite, which was being practiced in the past, was not correcting most of the feet, which would end up requiring surgery to be conducted by the few orthopaedic surgeons at Mulago.

The USCCP has adapted a Public Health Approach to solve the burden of neglected clubfeet in Uganda.

It was adapted following the Levine's Principle (JBJS). Which identified the problem and through consensus identified the solution.

It is hoped that early detection by the midwives or nurses and the community, and referral for treatment at the clubfoot clinics equipped with trained staff and consistent supply chain in a sustainable manner, and proper supervision and follow up of the cases will result in elimination of the neglected club feet in Uganda.

\section{CONCLUSION}

The Uganda sustainable Clubfoot Project, following a public health approach is a promising method for elimination of neglected clubfoot deformity. Strict adherence to the detail of Ponseti method produces excellent results.

The following recommendations are emphasized

1. Early detection

2. Early treatment
3. Ponseti Method to be routine in all Uganda hospitals from Health Center IV to National Referral Hospitals.

4. Efficient supply chain of Plaster of Paris and the Abduction foot Braces.

5. CMEs and Training of health workers for detection and treatment

6. Public awareness drive

\section{ACKNOWLEDGEMENTS}

I would like to acknowledge the management and Staff of the Uganda Sustainable Clubfoot Project for their active involvement in the struggle to eliminate the neglected clubfoot deformity in Uganda. Special Thanks to Prof. Shafique Pirani who introduced the Idea to establish the USCCP, The Orthopaedic coordinator, Dr.Gonzaga Waiswa, and his Team comprising of Mr.Musoke and Dirisa Kitemagwa for their active involvement in running the clinics, teaching, collecting Data, and Support supervision, Mrs. Mariek, the project coordinator, Prof Konde Lule and Stella for the Ethno cultural survey and incidence survey, last but not list, to CIDA Canada and Enable Canada, who are the main Funders of this project Makerere University, University of British Columbia, Ministry of Health Uganda, and Children's orthopaedic Rehabilitation Unit of Mengo Hospital(CORU) who are the collaborators of the Project.

\section{REFERENCES}

1. Herring J.A. Tachdjian's pediatric orthopaedics, from the Texas Scottish Rite Hospital for children, 3rd Edition. 2: 922-957.

2. Patel M. and Herzenberg J. Clubfoot. Last updated March 2005. www.emedicine.com

3. Theuri M.J. The Idiopathic Clubfoot: Short-term results of treatment with the Ponseti Method at Mulago Hospital. Unpublished Masters Dissertation, Makerere University, July 2003.

4. Vitale M.G .Patient-based outcomes following clubfoot surgery, A 16-year follow-up study. J. Pediat. Orthop. 2005; 25: 533-538.

5. Atria. Uganda Society For Disabled Children 1994 Annual Report.

6. Uganda Census Data, 2002.

7. Tindale A.J., Steinlechner C.W.B., Lavy C.B.D., Mannion S. and Mkandawire. Results of manipulation of Idiopathic clubfoot deformity in Malawi by orthopaedic clinical 
officers using the Ponseti method; A realistic alternative for the developing World? J. Paediat. Orthop. 2005; 25(5): 627-629.

8. McKay D.W. New concept of and approach to clubfoot treatment: Correction of the Clubfoot. J. Pediat. Orthop. 1983; 3(1): 10-21.

9. Cooper D.M. and Dietz F.R. Treatment of idiopathic clubfoot. A thirty year follow-up note. J. Bone \& Joint Surg. 1995; 77A(10): 1477-1489.

10. Kite J.H. Non-operative treatment of congenital clubfoot. Clin. Orthop. 1972; 84: 29-38.

11. Pirani S. Pirani severity scoring. In: Staheli L., Ed. Clubfoot; Ponseti Management. Glogal-HELP. 2003; 22-23.

12. Ponseti I.V. Congenital clubfoot: Fundamentals of treatment. Oxford University Press Inc., New York, 1996; 61-97.

13. Ponseti I.V. Current concepts review: Treatment of congenital clubfoot. J. Bone \& Joint Surg. 1992; 74A(3): 448-454.
14. Tindall A.J., Steinlechner C.W.B., Lavy C.B.D., Mannion S. and Mkandawire N. Results of manipulation of idiopathic clubfoot deformity in Malawi by clinical officers using the Ponseti method. J. Pediat. Orthop. 2005; 25(5): 627-629.

15. Sagev E., Keret D., Lkiee F., Yavor A., Weintroub S., Ezra E. and Hayek S. Early experience with the Ponseti method for the treatment of congenital idiopathic clubfoot. Israel Med. Ass. J. 2005; 7: 307-310.

16. Ponseti I.V. and Simoly E.N. Congenital clufoot. The results of treatment. J. Bone \& Joint Surg. 1963; 45A(2): 261-275.

17. Ippolito E., Farsetti P., Caterini R., Tudisco C. Long-term comparative results in patients with congenital clubfoot treated with two different protocals. J. Bone \& Joint Surg. 2003; 85A(7): 1286-1294.

18. Ponseti I.V. Congenital clubfoot: Fundamentals of treatment. Oxford University PressInc. New York, 1996; 1-7.

19. Staheli L. Ponseti clubfoot management. Teaching Manual for Health Care Providers in Uganda (Draft). 